\title{
Spectrofluorimetric Determination of Hydrochlorothiazide by a Carbon Dots-Based Probe via Inner Filtering Effect and Resonance Rayleigh Scattering
}

\author{
Ali Ghafarloo, ${ }^{\circledR a}$ Reza E. Sabzi, ${ }^{\odot * a}$ Naser Samadia and Hamed Hamishehkar ${ }^{b}$ \\ ${ }^{a}$ Department of Chemistry, Faculty of Science, Urmia University 5756151818, Urmia, Iran \\ ${ }^{b}$ Drug Applied Research Center, Tabriz University of Medical Sciences 5166614766, Tabriz, Iran
}

\begin{abstract}
Synthesis of carbon dots (CDs) from natural resources not only enables green synthesis and production of environmentally friendly materials, but also provides a cost-effective probe as a fluorescence nanosensor. The proposed sensor introduces a unique one-pot hydrothermal CDs synthesis from alfalfa leaves, which is promising for sensing hydrochlorothiazide (HCTZ) via inner filter effect (IFE) and resonance Rayleigh scattering (RRS). The as-prepared CDs had wide emission spectra, excitation-dependent emission, high solubility, high stability, and visible fluorescence light with a quantum yield of up to $11 \%$. The absorption of HCTZ overlapped with the excitation spectra of CDs. Therefore, CDs represented excellent quenching due to IFE when HCTZ was gradually added. Furthermore, this fluorescent sensor was successfully used to quantify HCTZ in the linear ranges $\left(0.17-2.50 \mu \mathrm{g} \mathrm{mL}^{-1}\right)$ with the limit of detection of $0.11 \mu \mathrm{g} \mathrm{mL}^{-1}$. The sensing system was simple as no surface functionalization was required for CDs, leading to less laborious steps and more cost-effective synthesis. The reaction time was short, i.e., less than 2 min, indicating a simple approach for rapid analysis of HCTZ. By optimizing conditions, successful measurements were carried out on pharmaceutical tablets.
\end{abstract}

Keywords: carbon quantum dots, hydrochlorothiazide, fluorescent nano-probe, inner filter effect, resonance Rayleigh scattering

\section{Introduction}

Hydrochlorothiazide (HCTZ) is one of the antihypertensive drugs which is beneficial for lowering blood pressure. High blood pressure causes diseases such as heart attacks and kidney problems, which can even lead to premature death. Thus, using this drug is efficient to prevent some diseases with irreversible events. In this regard, an analytical chemist needs to design and construct a method to accurately determine HCTZ in pharmaceutical tablets.

Various methods were used to determine HCTZ, including spectrophotometric methods, ${ }^{1-4}$ voltammetry, ${ }^{5-7}$ reverse-phase high performance liquid chromatography (HPLC), ${ }^{8-11}$ capillary electrophoresis, ${ }^{12}$ modified carbon paste electrodes, ${ }^{12}$ etc. Spectrofluorimetric methods are more selective and sensitive compared to spectrophotometric methods. Moreover, it supplies sensors with low limits of detection. Besides, spectrofluorimetric sensors have fewer interfere from scattering lights. Scattering lights in

*e-mail: rezasabzi@yahoo.com Editors handled this article: Eduardo Carasek and Ivo M. Raimundo Jr. (Associate) absorption methods cause positive errors and provide a false value for the analyte concentration. Meanwhile, the fluorimetric method is a simple, fast, and low-cost method compared to other instrumental methods, as the analyte is determined with minimal sample preparation steps and easy instrument setup. According to our studies in the scientific literature, there are no similar methods on HCTZ determination based on fluorescent carbon dots (CDs).

Recently, as a new material for sensing, CDs have emerged and found many applications in the determination of ions, ${ }^{13-18}$ drugs, ${ }^{19-28}$ biological molecules, ${ }^{29-32}$ amino acids, ${ }^{33,34}$ and herbicides. ${ }^{35,36} \mathrm{CDs}$ have extraordinary characteristics such as high solubility, high stability, high biocompatibility, and low toxicity. However, previous fluorescent probes such as organic compounds and metal quantum dots suffer from mentioned characteristics which restrict their application in the field of sensing. Moreover, $\mathrm{CDs}$ are appropriate for surface passivation, ${ }^{2-4}$ surface modification, ${ }^{5-8}$ and size controlling. ${ }^{9,10}$ So, it enables a chemist to synthesize CDs with various properties. Therefore, doping with various heteroatoms such as nitrogen, sulfur, and phosphorous provide CDs with excellent properties. ${ }^{37}$ For example, nitrogen doping is more common because of the greatest similarity of nitrogen 
with carbon. $\mathrm{N}$-doped CDs provide fluorescent nanoprobes with a high quantum yield and rich functional groups. ${ }^{38}$ Thus, N-CDs are promising candidates for fluorescence sensors. In the present work, a fluorescent sensor based on CDs was designed and employed for HCTZ determination in pharmaceutical and urine samples. The proposed sensor is based on the inner filter effect (IFE) mechanism as well as reducing the resonance Rayleigh scattering (RRS) light. Figure 1 shows the molecular structure of HCTZ.<smiles>NS(=O)(=O)c1cc2c(cc1Cl)NCNS2(=O)=O</smiles>

Figure 1. Molecular structure of HCTZ.

\section{Experimental}

\section{Chemicals and reagents}

HCTZ has purchased from Merck Company (Darmstadt, Germany). Sodium hydroxide flakes, phosphoric acid solution (85 wt.\%), hydrochloric acid solution (36-38 wt.\%), and potassium dihydrogen phosphate anhydrous were also purchased from Merck (Darmstadt, Germany). Phosphate buffer solution $0.1 \mathrm{M}(\mathrm{pH}=7)$ was prepared from potassium dihydrogen phosphate with the assistance of sodium hydroxide and phosphoric acid solution as $\mathrm{pH}$ regulators. HCTZ was dissolved in methanol, and then water was poured into the volumetric flask for dilution to the desired level.

\section{Instrument}

UV-Vis spectra were recorded using a spectrophotometer equipped with a photodiode array detector (WPA Biowave, England). The functional groups of CDs were determined on a Fourier transform infrared spectrometer from Nicolet Thermo Company (NEXUS-670, USA) by preparing KBr pellets. The fluorescence spectra of all solutions were recorded on a JASCO FP-PC-6500 spectrofluorometer (Jasco, Tokyo, Japan) equipped with a $150-\mathrm{W}$ xenon lamp. The morphology of CDs was determined using transmission electron microscopy (Germany, Leo 906, Zeiss) at an accelerating voltage of $200 \mathrm{kV}$. pH levels of the samples were measured using a $\mathrm{pH}$-meter (Mettler Toledo, Switzerland).

\section{Preparation of fluorescent CDs}

In a typical procedure, CDs were synthesized from alfalfa leaves via a bottom-up approach via hydrothermal technique. At first, the leaves were washed with tap water and deionized water. The leaves were exposed to sunlight and then completely dried in an oven at $40{ }^{\circ} \mathrm{C}$ for 2 days. After drying, the leaves were crushed to a fine powder with a mortar. Then, $0.25 \mathrm{~g}$ of the powdered sample was mixed in $20 \mathrm{~mL}$ of deionized water. The sample solution was placed on an ultrasonic bath for $2 \mathrm{~h}$ and then transferred to an autoclave. Finally, the sample was placed in an autoclave for $6 \mathrm{~h}$ at $200{ }^{\circ} \mathrm{C}$ (Figure 2). A dark solution was obtained and filtered via a filter paper. It was then centrifuged at $10,000 \mathrm{rpm}$ to remove impurities. The sample solution was passed via the semi-permeable membrane, which particles larger than 3,000 Daltons could not pass. The membrane was immersed in deionized water for 2 days, and its water was changed several times. The resulting solution was used for further analysis.

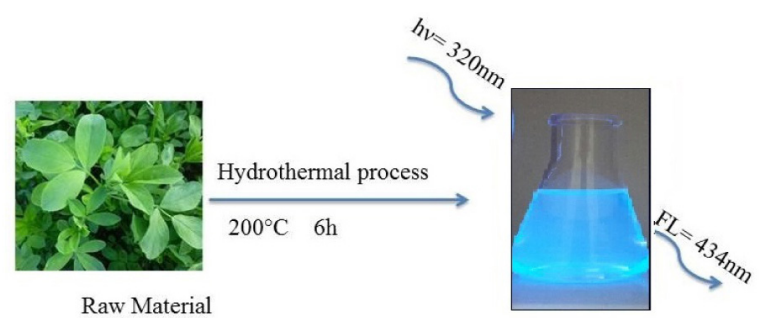

Figure 2. Synthesis procedure of CDs from alfalfa.

\section{Results and Discussion}

\section{Characterization}

One of the obvious evidence of the formation of CDs on the nanoscale is the presence of photoluminescence spectrum. Thus, this study used photoluminescence spectrum and UV-Vis absorption spectrum to confirm and characterize the synthesized CDs. Studies of the absorption spectra of CDs showed a shoulder at about $340 \mathrm{~nm}$ region related to electron promotion of $n-\pi^{*}$, and a peak at $270 \mathrm{~nm}$ related to electron promotion of $\pi-\pi^{*}$. The first electron promotion was related to $\mathrm{C}=\mathrm{N}$ or $\mathrm{C}=\mathrm{O}$ chromophores, and the second related to $\mathrm{C}=\mathrm{C}$ chromophores of aromatic structure.

Moreover, by selecting $310 \mathrm{~nm}$ as the excitation wavelength, a symmetric fluorescence peak appeared at $434 \mathrm{~nm}$ by a displacement of $124 \mathrm{~nm}$ at the maximum wavelength. The absorption and fluorescence spectra of CDs in deionized water are represented in Figure 3.

By changing the excitation wavelength to longer wavelengths, the synthetic CDs emission shifted to longer wavelengths. While by changing the excitation wavelength to shorter wavelengths, the synthetic CDs emission shifted to shorter wavelengths, and fluorescence 


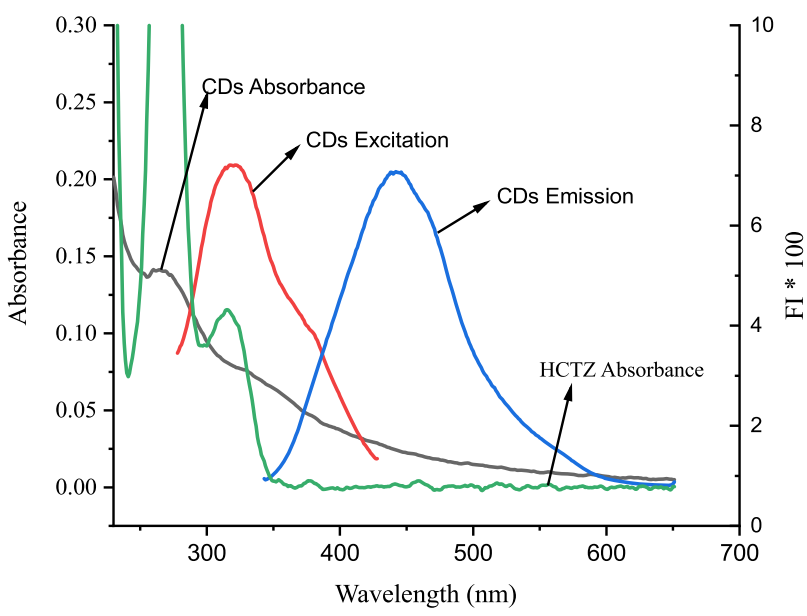

Figure 3. Fluorescence spectra of CDs emission and excitation as well as CDs and HCTZ absorbance.

intensities on both sides were reduced. This indicates one of the characteristics of CDs. Exciting CDs within the range from 280 to $450 \mathrm{~nm}$ with the $10-\mathrm{nm}$ interval, the maximum emission of CDs shifted from $420 \mathrm{~nm}$ to larger wavelengths of $550 \mathrm{~nm}$, while its emission intensity was gradually reduced (Figure 4a). This is due to existence of different surface groups which create different energy states. Therefore, the emission from different energy states results excitation-dependent CDs. ${ }^{39}$

To obtain more information about the structure of CDs and the dimensions of obtained CDs, transmission electron microscopy (TEM) studies were performed. Apparently, these studies revealed that the CDs were in symmetrical spherical shapes with the average size of $5 \mathrm{~nm}$. The TEM image of CDs is depicted in Figure 4b.

The type of functional groups present in the synthetic CDs was determined using infrared spectroscopy. CDs mostly consists of graphitic $\mathrm{sp}^{2}$-core surrounded by $\mathrm{sp}^{3}$-carbon matrix which possess a variety of functional groups like $\mathrm{O}-\mathrm{H}, \mathrm{C}=\mathrm{O}, \mathrm{C}-\mathrm{O}-\mathrm{C}, \mathrm{N}-\mathrm{H}$, etc. Graphitic $\mathrm{sp}_{2}$-core have no absorption band, but functional groups on the surface of $\mathrm{CDs}$ and exhibit absorption bands in the infrared spectrum. As can be seen in Figure 4c, the absorption peak at about $3463 \mathrm{~cm}^{-1}$ belongs to the $\mathrm{O}-\mathrm{H}$ and $\mathrm{N}-\mathrm{H}$ stretching vibrations. The two peaks at 2930 and $2850 \mathrm{~cm}^{-1}$ were related to $\mathrm{C}-\mathrm{H}$ stretching vibration. The intense band at $1705 \mathrm{~cm}^{-1}$ corresponded to $\mathrm{C}=\mathrm{O}$ stretched carboxylic acid or other carbonyl functional groups attached to the surface. The absorption band at about
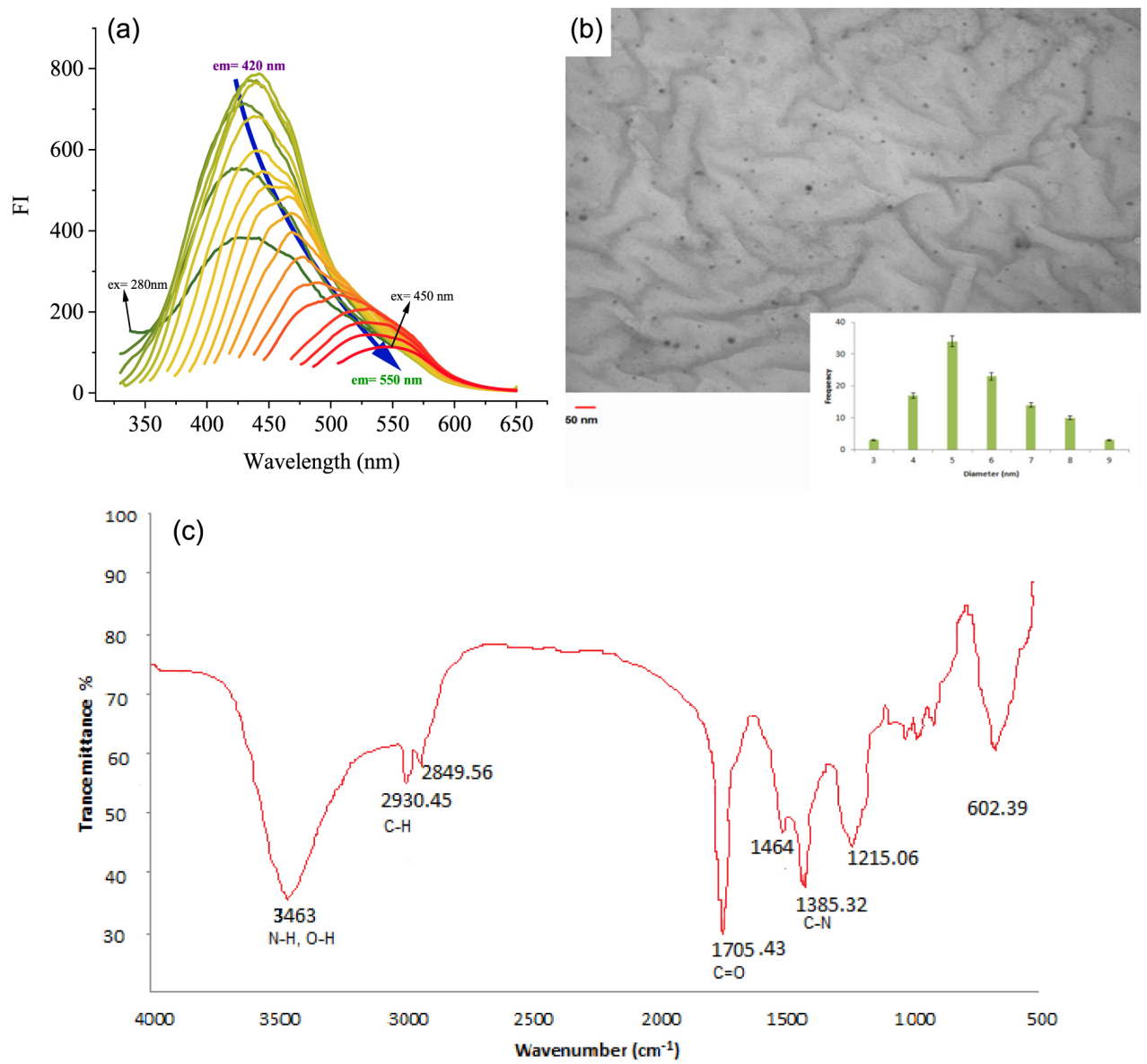

Figure 4. (a) Emission spectra of synthesis CDs at different excitation wavelengths (280-450 nm), (b) TEM image of CDs, (c) infrared spectra of CDs within $400-4000 \mathrm{~cm}^{-1}$. 
$1385 \mathrm{~cm}^{-1}$ was assigned to $\mathrm{C}-\mathrm{N}$ stretching vibration. Thus, the results obtained from infrared spectra indicate that the surfaces of CDs included hydrophilic groups such as hydroxyl, carboxylic acid, and amine. The presence of these groups on the surface increases the solubility of CDs in water.

\section{Optimizing CDs concentration}

According to Figure 5A, fluorescence intensity based on the concentration of synthetic CDs shows a maximum in the linear graph which then deviates from the linear mode because of the self-absorption of CDs. The maximum concentration obtained in diagram is the concentration which CDs exhibit high sensitivity and wider linear range. Therefore, a concentration of $0.6 \mathrm{mg} \mathrm{mL}^{-1}$ was selected for further measurements.

\section{$\mathrm{pH}$ measurement}

The effect of different $\mathrm{pH}$ was investigated on the detection and measurement of HCTZ using synthetic CDs from alfalfa. At first, the $\mathrm{pH}$ of the CDs solution was adjusted within 3-11 using $0.1 \mathrm{M}$ phosphate buffer. Then, the fluorescence intensity was recorded before and after adding HCTZ to the solution containing CDs. As seen in
Figure 5B, the highest fluorescence intensity was obtained at $\mathrm{pH}$ between 5 and 7 . Thus, $\mathrm{pH}=7$ was considered as the optimal $\mathrm{pH}$ for future studies. Moreover, $\mathrm{pH}$ had the same effect on the CDs' intensity and CDs in the presence of HCTZ. Indeed, the intensity difference of the two measurements was equal at every $\mathrm{pH}$. This indicates that the $\mathrm{pH}$ does not interfere with HCTZ measurement.

\section{Reaction time}

The reactivity of sensor was also investigated (Figure 5C). After adding HCTZ, CDs solution was stirred to be homogenized. Then, the fluorescence intensity was measured. The results indicated that HCTZ interaction was rapid, and the reaction reached equilibrium in less than 1 min.

\section{Quantum yield}

Quantum yield (QY) was calculated using quinine sulfate $(\mathrm{QY}=0.54$ and sulfuric acid solvent $0.1 \mathrm{M}))^{3,32}$ At first, quinine sulfate and CDs solution were prepared, and their concentrations were adjusted to give adsorption below 0.1 to reduce the reabsorption effects (Figure S1, Supplementary Information (SI) section). Then, the
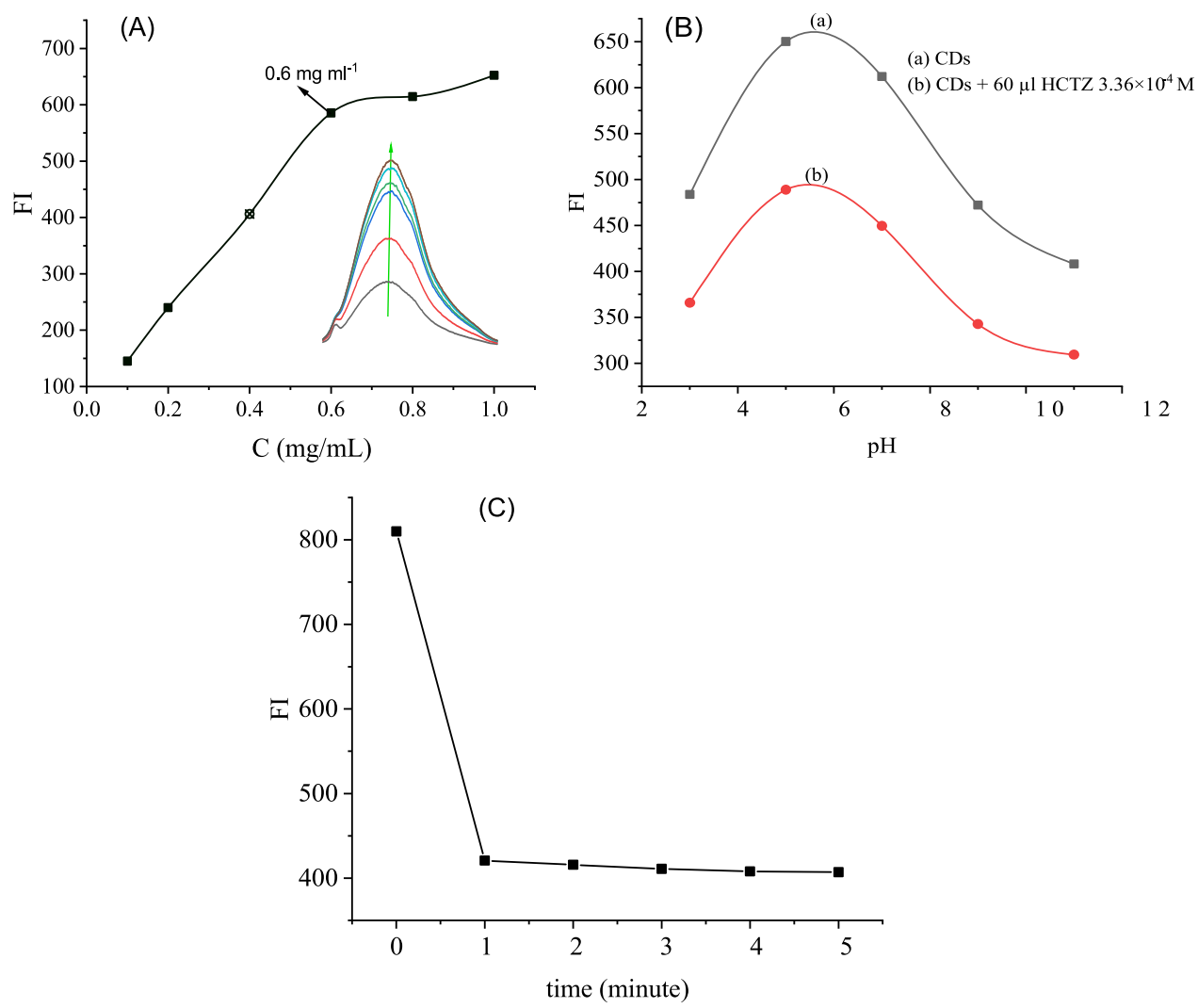

Figure 5. (A) Fluorescence spectra and curve at various concentrations of CDs in water $\left(0.1,0.2,0.4,0.6,0.8\right.$ and $\left.10.0 \mathrm{mg} \mathrm{mL}^{-1}\right)$, (B) fluorescence spectra of CDs $\left(0.6 \mathrm{mg} \mathrm{mL}^{-1}\right)$ and CDs in presence of $\mathrm{HCTZ}\left(3.36 \times 10^{-4}\right)$ at different pHs between 3 and 11, (C) fluorescence response time curve. 

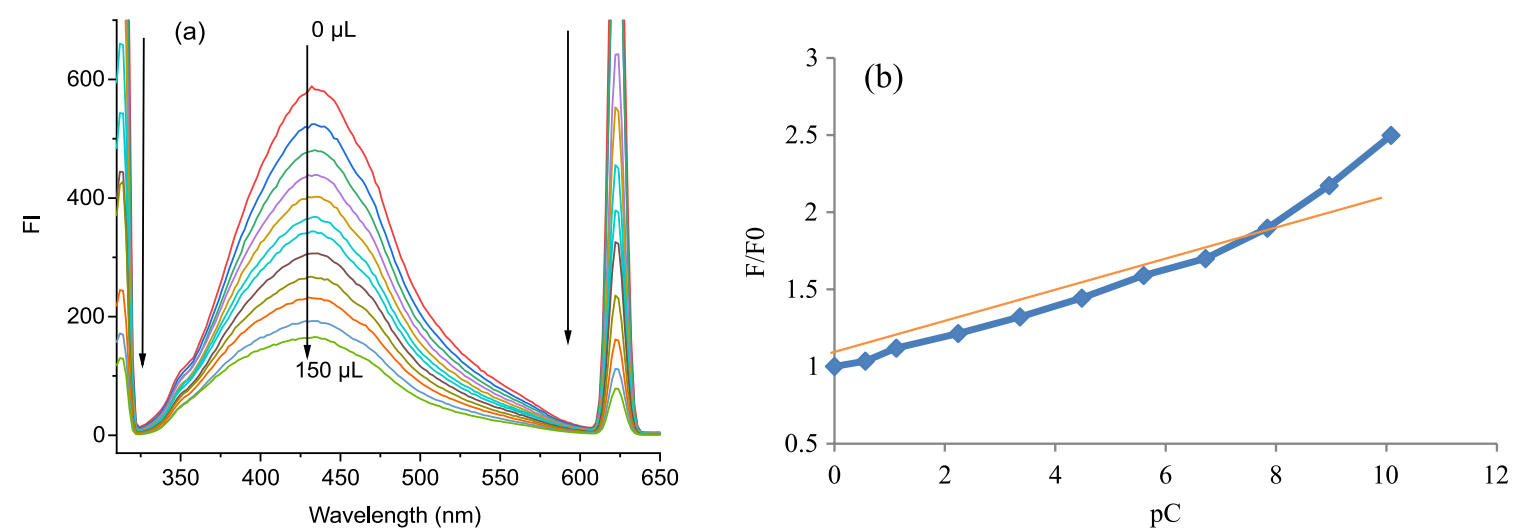

Figure 6. (a) Fluorescence emission spectra of CDs at different concentrations of HCTZ $\left(0.0,5.6 \times 10^{-7}, 1.1 \times 10^{-6}, 2.2 \times 10^{-6}, 3.4 \times 10^{-6}, 4.5 \times 10^{-6}\right.$, $5.6 \times 10^{-6}, 6.7 \times 10^{-6}, 7.8 \times 10^{-6}, 9.0 \times 10^{-6}, 10 \times 10^{-6} \mathrm{M}$ ) in phosphate buffer solution $\mathrm{pH}=7$ and (b) calibration curve.

emission spectra (Figures S2 and S3, SI section) of both were recorded at the excitation wavelength of $320 \mathrm{~nm}$, and the quantum yield was calculated using equation 1 .

$\varphi_{S}=\varphi_{R} \times\left(\frac{I_{S}}{I_{R}}\right) \times\left(\frac{A_{R}}{A_{S}}\right) \times\left(\frac{\eta_{S}}{\eta_{R}}\right)^{2}$

In this equation, I represents the area below the fluorescence spectrum curve, $\eta$ represents the refractive index, and $\mathrm{A}$ denotes the absorption. The letters $\mathrm{S}$ and $\mathrm{R}$ are the values for the sample and the standard, respectively.

\section{HCTZ determination}

HCTZ was successfully measured using CDs via spectrofluorimetry. As seen in Figure 6a, a gradual decrease in fluorescence intensity and RRS is observed with the gradual increase of HCTZ concentration in the cell containing CDs. The calibration curve is linear within the concentration range from $5.6 \times 10^{-7}-8 \times 10^{-6} \mathrm{M}$ and is suitable for measuring HCTZ (Figure 6b). In this method, CDs solution was prepared in $0.1 \mathrm{M}$ phosphate buffer solution with $\mathrm{pH}=7$ and stored in laboratory media for $2 \mathrm{~h}$. Then, $3 \mathrm{~mL}$ of CDs solution was added to the fluorimetric cell, and its intensity was recorded. Finally, a certain volume of HCTZ prepared in acetonitrile solvent was added to the cell containing carbon dot, and emission was measured after the complete stirring of solution.

\section{Mechanism of HCTZ}

HCTZ mechanism was verified via spectrofluorimetry, spectrophotometry, and $\mathrm{pH}$ investigation through fluorescence measurements in the presence and absence of HCTZ. These methods indicate that the provided sensor behaved based on the IFE mechanism.
First, the UV-Vis spectra investigation showed no difference between the binary mixture of CDs and HCTZ and the sum of the isolated spectra of two components. The two spectra were the same (Figure 7), suggesting no interaction between the probe and analyte (see "Mixture analysis" sub-section at SI section). Secondly, the investigation of excitation spectra of CDs and absorbance spectra of HCTZ indicated that there is overlapping between the two spectra (Figure 3). This illustrates that HCTZ could absorb the excitation wavelength. Hence, the fluorescence intensity of CDs would decrease when the concentration of HCTZ increased in the fluorimetric cell. Besides, the results obtained from spectrofluorimetric titration of CDs confirm this mechanism. Moreover, fluorescence intensity and resonance Rayleigh spectra in the first (310-325 nm) and second-order $(610-630 \mathrm{~nm})$ RRS spectra of CDs were reduced by adding HCTZ. Thus, it means that the proposed sensor mechanism is based on IFE. Finally, the fluorescence of CDs and CDs in the presence of HCTZ was examined at different $\mathrm{pH}$ (Figure 5b). The difference between the two spectra is constant in all $\mathrm{pH}$. So, it means there is no interaction with CDs and HCTZ.

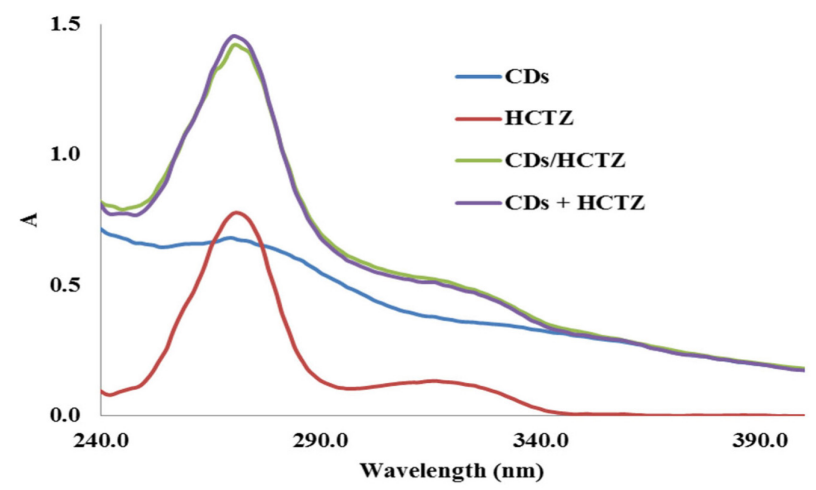

Figure 7. UV-Vis spectra of CDs, HCTZ, the mixture of both solutions $\mathrm{CDs} / \mathrm{HCTZ}$, and the result of adding up the spectrum of each isolated compound (CDs + HCTZ). 
As the fluorescence intensity decreased, so did the RRS spectra. Thus, these observations indicate that the proposed sensor mechanism is based on IFE.

\section{Selectivity and sensitivity}

This section examines the interaction of several ionic compounds such as $\mathrm{Ca}^{2+}, \mathrm{Mg}^{2+}, \mathrm{Zn}^{2+}, \mathrm{Na}^{+}$and $\mathrm{K}^{+}$and compounds in the formulation of HCTZ tablets (starch, fructose, glucose, sucrose and lactose). These compounds are likely to be present in the analysis of the medium. First, the interfering compounds were separately added to CDs containing cells, and their interaction was investigated (Figure 8). The results showed that only in the presence of HCTZ, the fluorescence intensity was significantly reduced. Then, the mixture of interfering compounds in the presence and absence of HCTZ was added to the cell containing CDs (Figure 9). The results showed the CDs exhibited a selective behavior. The reliability of proposed sensor was examined in real sample such as HCTZ tablets.

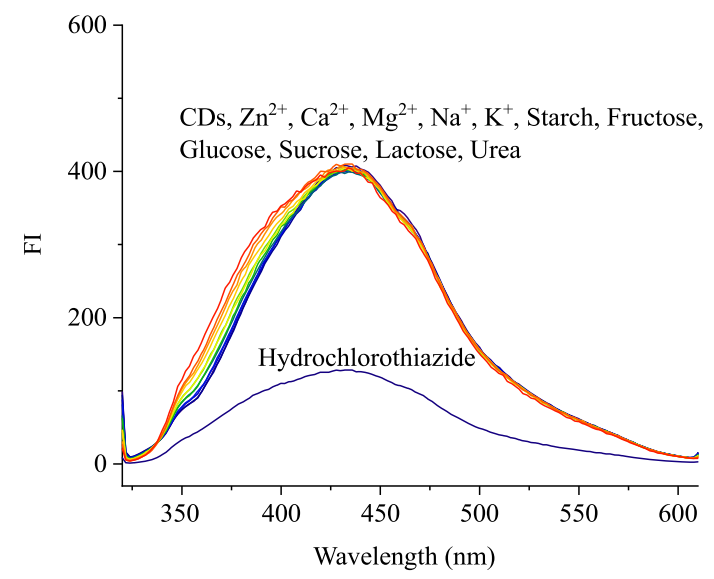

Figure 8. Fluorescence intensity of CDs in the presence of different interfering substances.

\section{Real sample analysis}

To evaluate the practical application of this method, HCTZ content in its tablets was measured by the standard

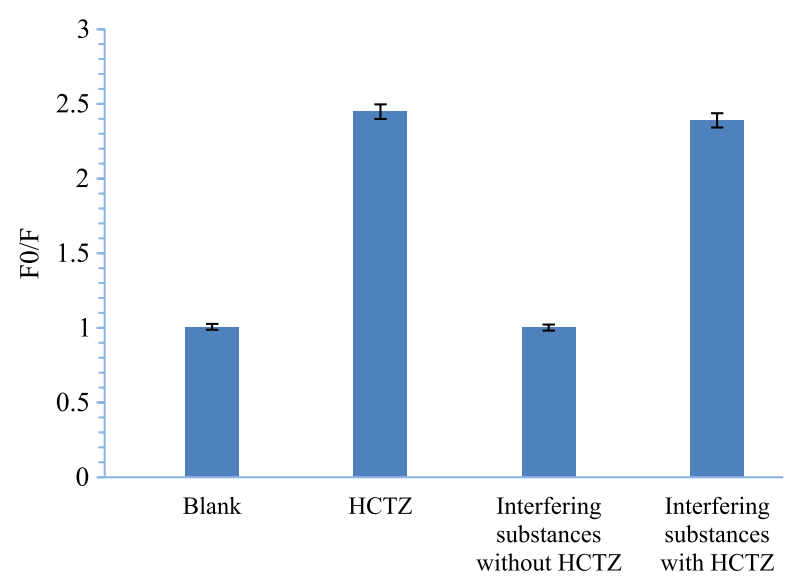

Figure 9. Fluorescence ratio of interfering substances in the presence and absence of HCTZ.

addition method (Table 1). HCTZ $25 \mathrm{mg}$ tablets were selected and ground in a mortar. The weight of sample equivalent to $10 \mathrm{mg}$ of HCTZ was then carefully weighed and placed into a $100 \mathrm{~mL}$ volumetric flask. Methanol was added to the sample and stirred on a stirrer for half an hour to completely release the HCTZ. After stirring, $100 \mathrm{~mL}$ of the volumetric flask was taken for dilution with methanol. The obtained solution was filtered via filter paper and used for subsequent measurements.

Table 1. Determination of HCTZ in pharmaceutical tablets

\begin{tabular}{lccccc}
\hline No. & Sample & $\begin{array}{c}\text { Added / } \\
\mu \mathrm{M}\end{array}$ & $\begin{array}{c}\text { Expected / } \\
\mu \mathrm{M}\end{array}$ & $\begin{array}{c}\text { Found / } \\
\mu \mathrm{M}\end{array}$ & $\begin{array}{c}\text { Recovery / } \\
\%\end{array}$ \\
\hline 1 & & 1.12 & 1.79 & 1.85 & 103.3 \\
2 & \multirow{2}{*}{ tablet } & 3.36 & 4.03 & 4.09 & 101.5 \\
3 & & 5.60 & 6.27 & 6.12 & 97.6 \\
4 & & 7.84 & 8.51 & 8.33 & 97.9 \\
\hline
\end{tabular}

\section{Comparison with other techniques}

A comparison between this method and the spectrophotometric method (Table 2) revealed that this method had a lower limit of detection. Besides, this approach is simple and cost-effective compared to instrumental techniques such as HPLC and voltammetry techniques.

Table 2. Comparison of the proposed sensor with other methods of HCTZ determination

\begin{tabular}{|c|c|c|c|c|}
\hline Method & Limit of detection & Linear range & $\mathrm{RSD} / \%$ & Reference \\
\hline Spectrophotometric method & $0.1 \mathrm{mg} \mathrm{mL}^{-1}$ & $4-20 \mathrm{mg} \mathrm{mL}^{-1}$ & 0.32 & 1 \\
\hline Spectrophotometric method & $1.1 \mu \mathrm{g} \mathrm{mL}^{-1}$ & $1.5-15.0 \mu \mathrm{g} \mathrm{mL}^{-1}$ & 1.22 & 3 \\
\hline Spectrophotometric method & $0.62 \mu \mathrm{g} \mathrm{mL}^{-1}$ & $2-10 \mu \mathrm{gLL}^{-1}$ & 4.66 & 4 \\
\hline Voltammetry & $0.35 \mu \mathrm{g} \mathrm{mL}^{-1}$ & $0.89-22.03 \mu \mathrm{g} \mathrm{mL}{ }^{-1}$ & 2.70 & 6 \\
\hline Voltammetry & $0.05 \mu \mathrm{g} \mathrm{mL}^{-1}$ & $0.1-210 \mu \mathrm{g} \mathrm{mL}^{-1}$ & 2.26 & 7 \\
\hline HPLC & $0.03 \mu \mathrm{g} \mathrm{mL}^{-1}$ & $0.01-1.2 \mu \mathrm{g} \mathrm{mL}^{-1}$ & 3.10 & 8 \\
\hline HPLC-mass spectrometry & $0.51 \mathrm{ng} \mathrm{mL}^{-1}$ & $1.0-112 \mathrm{ng} \mathrm{mL}^{-1}$ & 2.99 & 40 \\
\hline Spectrofluorimetry & $0.11 \mu \mathrm{g} \mathrm{mL}^{-1}$ & $0.17-2.50 \mu \mathrm{g} \mathrm{mL}^{-1}$ & 2.4 & this work \\
\hline
\end{tabular}

RSD: relative standard deviation; HPLC: high performance liquid chromatography. 
Therefore, sensitive and cost-effective determination of HCTZ is possible compared to spectrophotometric and instrumental methods.

\section{Conclusions}

In general, a new sensitive sensor was used to the assay of HCTZ in real samples based on the IFE mechanism. CDs was synthesized from natural resources by hydrothermal process and purified. Its concentration was optimized and $\mathrm{pH}$ measurements investigated. The proposed sensor showed fast response time and quantum yield up to $11 \%$. The results indicated that the fluorescence intensity of CDs quenched as the HCTZ concentration increased in the fluorimetric cell as well as resonance Rayleigh spectra in the first and second-order spectra. The limit of detection of the proposed sensor was $0.11 \mu \mathrm{g} \mathrm{mL}^{-1}$ and it was employed for sensitive determination in real samples with reliable results. Furthermore, this method is remarkably simple, fast, cheap, and environmentally friendly.

\section{Supplementary Information}

Supplementary data are available free of charge at http:// jbcs.sbq.org.br as PDF file.

\section{Acknowledgments}

The authors acknowledge the financial support from the Department of Analytical Chemistry, Faculty of Chemistry, Urmia University, Urmia, Iran, and the Drug Applied Research Center, Tabriz University of Medical Sciences, Tabriz, Iran.

\section{References}

1. Deng, L.; Yuan, Y.; Zhang, Y.; Wang, Y.; Chen, Y.; Yuan, H.; Chen, Y.; ACS Sustainable Chem. Eng. 2017, 5, 9766.

2. Wang, Z.; Long, P.; Feng, Y.; Qin, C.; Feng, W.; RSC Adv. 2017, 7, 2810.

3. Pan, J.; Zheng, Z.; Yang, J.; Wu, Y.; Lu, F.; Chen, Y.; Gao, W.; Talanta 2017, 166, 1.

4. Radhakrishnan, K.; Panneerselvam, P.; Marieeswaran, M.; Anal. Methods 2019, 11, 490.

5. Shen, P.; Xia, Y.; Anal. Chem. 2014, 86, 5323.

6. Yan, F.; Ye, Q.; Xu, J.; He, J.; Chen, L.; Zhou, X.; Sens. Actuators, B 2017, 251, 753.

7. Krishna, A. S.; Radhakumary, C.; Antony, M.; Sreenivasan, K.; J. Mater. Chem. B 2014, 2, 8626.

8. Gao, K.; Guo, Y.; Niu, Q.; Han, L.; Zhou, L.; Wang, L.; Sens. Actuators, B 2018, 262, 298.
9. Hu, C.; Yu, C.; Li, M.; Wang, X.; Yang, J.; Zhao, Z.; Eychmüller, A.; Sun, Y. P.; Qiu, J.; Small 2014, 10, 4926.

10. Huang, Z.; Lin, F.; Hu, M.; Li, C.; Xu, T.; Chen, C.; Guo, X.; J. Lumin. 2014, 151, 100.

11. Rane, V.; Sangshetti, J.; Shinde, D.; J. Chromatogr. Sci. 2008, 46, 887.

12. Karimi-Maleh, H.; Ensafi, A. A.; Ensafi, H. R.; J. Braz. Chem. Soc. 2009, 20, 880.

13. Wang, F.; Hao, Q.; Zhang, Y.; Xu, Y.; Lei, W.; Microchim. Acta 2016, 183, 273.

14. Yazid, S. N. A. M.; Chin, S. F.; Pang, S. C.; Ng, S. M.; Microchim. Acta 2013, 180, 137.

15. Bhamore, J. R.; Jha, S.; Park, T. J.; Kailasa, S. K.; Sens. Actuators, B 2018, 277, 47.

16. Yue, J.; Li, L.; Cao, L.; Zan, M.; Yang, D.; Wang, Z.; Chang, Z.; Mei, Q.; Miao, P.; Dong, W.-F.; ACS Appl. Mater. Interfaces 2019, 11, 44566.

17. Vaz, R.; Bettini, J.; Júnior, J. G. F.; Lima, E. D. S.; Botero, W. G.; Santos, J. C. C.; Schiavon, M. A.; J. Photochem. Photobiol., A 2017, 346, 502.

18. Wang, Q.; Zhang, S.; Ge, H.; Tian, G.; Cao, N.; Li, Y.; Sens. Actuators, B 2015, 207, 25.

19. Zhang, Y.; Gao, Z.; Zhang, W.; Wang, W.; Chang, J.; Kai, J.; Sens. Actuators, B 2018, 262, 928.

20. Zeng, H.; Li, L.; Ding, Y.; Zhuang, Q.; Talanta 2018, 178, 879.

21. Shariati, R.; Rezaei, B.; Jamei, H. R.; Ensafi, A. A.; Talanta 2019, 194, 143.

22. Song, J.; Liang, X.; Ma, Q.; An, J.; Feng, F.; Spectrochim. Acta, Part A 2019, 216, 296.

23. Azizi, B.; Farhadi, K.; Samadi, N.; Microchem. J. 2019, 146, 965.

24. Zhang, Y.; Gao, Z.; Yang, X.; Yang, G.; Chang, J.; Jiang, K.; RSC Adv. 2019, 9, 6084.

25. Chullasat, K.; Kanatharana, P.; Bunkoed, O.; Sens. Actuators, B 2019, 281, 689.

26. Amin, N.; Afkhami, A.; Hosseinzadeh, L.; Madrakian, T.; Anal. Chim. Acta 2018, 1030, 183.

27. Zhang, Z.; Chen, J.; Duan, Y.; Liu, W.; Li, D.; Yan, Z.; Yang, K.; J. Lumin. 2018, 33, 318.

28. Ghafarloo, A.; Sabzi, R. E.; Samadi, N.; Hamishehkar, H.; J. Photochem. Photobiol., A 2020, 388, 112197.

29. Rossini, E. L.; Milani, M. I.; Pezza, H. R.; Talanta 2019, 201, 503.

30. Zhu, J.; Chu, H.; Shen, J.; Wang, C.; Wei, Y.; J. Colloid Interface Sci. 2021, 586, 683.

31. Luo, X.; Zhang, W.; Han, Y.; Chen, X.; Zhu, L.; Tang, W.; Wang, J.; Yue, T.; Li, Z.; Food Chem. 2018, 258, 214.

32. Barati, A.; Shamsipur, M.; Abdollahi, H.; Biosens. Bioelectron. 2015, 71, 470 .

33. Amjadi, M.; Abolghasemi-Fakhri, Z.; Hallaj, T.; J. Photochem. Photobiol., A 2015, 309, 8. 
34. Mu, Z.; Hua, J.; Feng, S.; Yang, Y.; Spectrochim. Acta, Part A 2019, 219, 248.

35. Gogoi, J.; Chowdhury, D.; J. Mater. Sci. 2020, 55, 11597.

36. Yuan, Y.; Jiang, J.; Liu, S.; Yang, J.; Yan, J.; Hu, X.; Sens. Actuators, B 2017, 242, 545.

37. Yan, F.; Sun, Z.; Zhang, H.; Sun, X.; Jiang, Y.; Bai, Z.; Microchim. Acta 2019, 186, 583.

38. Xu, Q.; Kuang, T.; Liu, Y.; Cai, L.; Peng, X.; Sreeprasad, T. S.; Zhao, P.; Yu, Z.; Li, N.; J. Mater. Chem. B 2016, 4, 7204.
39. Barman, M. K.; Patra, A.; J. Photochem. Photobiol., C 2018, 37,1 .

40. Tutunji, L. F.; Tutunji, M. F.; Alzoubi, M. I.; Khabbas, M. H.; Arida, A. I.; J. Pharm. Biomed. Anal. 2010, 51, 985.

Submitted: May 17, 2021 Published online: November 18, 2021 